Portland State University

PDXScholar

3-2-2018

\title{
Discrimination Against Healthcare Providers: Through Training and Practice
}

Shawna Erickson

Portland State University

Follow this and additional works at: https://pdxscholar.library.pdx.edu/honorstheses Let us know how access to this document benefits you.

\section{Recommended Citation}

Erickson, Shawna, "Discrimination Against Healthcare Providers: Through Training and Practice" (2018). University Honors Theses. Paper 517.

https://doi.org/10.15760/honors.522

This Thesis is brought to you for free and open access. It has been accepted for inclusion in University Honors Theses by an authorized administrator of PDXScholar. Please contact us if we can make this document more accessible: pdxscholar@pdx.edu. 
Discrimination Against Healthcare Providers: Through Training and Practice

by

\section{Shawna Erickson}

An undergraduate honors thesis submitted in partial fulfillment of the requirements for the degree of

Bachelor of Science

in

University Honors

and

Psychology

Thesis Adviser

Kerth O'Brien, $\mathrm{PhD}$

Portland State University 


\section{What is going on?}

In general, discrimination and prejudice are often interchanged definitionally. According to the Encyclopedia of Social Psychology (2007), discrimination is defined as: "the phenomenon of treating a person differently from other persons based on group membership and an individual's possession of certain characteristics such as age, class, gender, race, religion, and sexuality" (Baumeister \& Vohs, 2007). In other words, it is an "unjustified negative behavior toward a group or its members" (Myers \& Twenge, 2017, p.256). Prejudice is defined as "an attitude toward people based on their membership in a group" and is most often a negative attitude, though can be positive (Baumeister \& Vohs, 2007). "Whereas discrimination involves a behavioral response of a person to a member of a group or to a group as a whole. . prejudice [is an] intrapsychic [phenomenon]" (Fiske, Gilbert, Lindzey, \& Jongsma, 2010, p.1085). In short, prejudice is a negative attitude and discrimination is a negative behavior. For the purposes of this literature review, there will be a strong focus on the discriminatory behaviors that the students, residents, and physicians face versus prejudicial attitudes alone.

Discrimination can be subdivided into two separate forms as well: individual and institutional. Individual level discrimination is the discriminatory behavior between persons, one to another (Baumeister \& Vohs, 2007). Institutional level discrimination is when a company or government agency discriminates against a specific group of people as a whole (Baumeister \& Vohs, 2007). Although most evidence pertains to individual level discrimination, some evidence also exists concerning institutional level discrimination in the medical profession, and when discussed in this literature review it will be noted.

In empirical research, the context of the felt experience of discrimination cannot completely be known. In some instances of discrimination, the unjust circumstance night not be recognized by the discriminated target. Plausibly, in other circumstances, a person might believe they have been the target of discrimination while most other members of their target group would not see discrimination in the same circumstance. Although imperfect, the measure of discrimination typically relies on measures of perceived discrimination. As Coombs and King (2005) discuss, "discrimination towards an individual is a subjective experience and is based on the perception of one or more individuals. . discrimination may be intermittent or pervasive, subtle or overt" (Coombs \& King, 2005).

The literature on this topic is mostly gray depending on the subject. Gray literature is defined by California State University (2017) as "literature (often scientific or technical) that is not available through the usual bibliographic sources such as databases or indexes" (Outten, 2017). Outten discusses how such literature can be produced by many agencies, corporations, research centers, and professional organizations. It may not be scholarly (peer-reviewed) but it is produced by researchers and practitioners in the field. It can be produced more quickly and may even be more detailed than other types of literature (Outten, 2017). Medical students and residents have had a fair amount of quantitative and qualitative peer-reviewed studies addressing their experiences, whereas information for physicians that face discrimination comes mostly from self-reports on blogs or other sources of media which are some avenues of gray literature. For this paper, it will be assumed that information pertaining to medical students and residents 
will be peer-reviewed published literature unless otherwise stated. For practicing physicians, most of the literature and examples presented in this literature review can be assumed to be gray literature unless otherwise noted.

It is noteworthy to mention that papers that have been published since about the early 1980s through now on this topic have not seemingly reached a consensus on how to describe the negative behaviors present in the medical system. Some studies distinguish between harassment and discrimination, discuss solely harassment, abuse, mistreatment, or mistreatment and discrimination. The most recent studies focus more on mistreatment as an umbrella term for discriminatory acts. It seems that most of the time the terms mean the same thing and can be used interchangeably. Only in some instances a clear line can be seen between sexual harassment and gender discrimination, which still equate to mistreatment for the purpose of that paper (Mavis, Sousa, Lipscomb, \& Rappley, 2014). For the purpose of the current paper however, negative behaviors to be covered will be referred to as discriminatory behaviors unless otherwise noted. The majority of these studies do not come from social psychologists in particular which may explain the frequent discrepancy in the terms.

The objective of this literature review is to assess previous work and look for commonalities and patterns of reported discriminatory behavior. The goal is to understand the types of discrimination physicians and medical students/residents face, how discrimination negatively impacts their work, from whom this discrimination originates, and how this problem can be addressed.

II. Why is this important?

Medical students, residents, and practicing physicians face a lot of stressors. These include burnout as students, residents, and physicians (Amanullah, McNally, Zelin, Cole, \& Cernovsky, 2017; Dyrbye, Thomas, \& Shanafelt, 2005); cynicism as a student and into residency and beyond (Dyrbye et al., 2005), compassion fatigue as a physician (Jablow, 2017), and other stressors in their personal lives such as death of a family member or a change in one's health (Dyrbye et al., 2005). Dyrbye and colleagues also discuss other sources of stress as a student, for example, first encounters of death and suffering, educational debt, ethical conflicts, and just overall adjustment to the medical school environment (Dyrbye et al., 2005). In a quantitative study by Fahrenkopf et al. (2008) in which nurses and physicians were hired and trained to monitor residents' medication errors at 3 different medical schools, investigators found that overall from the self-reports and data collected, $20 \%$ of residents were suffering from depression and $75 \%$ were burnt out. Those that were depressed made six times more medication errors than those that were not depressed. Burnout, although more common than depression, had no association with medication errors, however those suffering from burnout were more likely to report significantly more medical errors compared to those who were not burnt out. They also discuss how residents who were burnt out or depressed were more likely to report poorer health and higher error rates than those who were not (Fahrenkopf et al., 2008).

Discrimination is one more thing to compete with, almost on a daily basis depending on how someone else interprets a physician's or student's specific physical characteristics. The 
stress from discrimination along with other job and life stressors these trainee's and providers face is dangerous and can cause many problems, considering their jobs are to manage peoples' lives. It has been described that those facing discrimination have higher rates of suicide, substance abuse, high rates of cynicism, impaired academic performance (for medical students) (Dyrbye et al., 2005), and misdiagnosing a patient (Crutcher, Szafran, Woloschuk, Chatur, \& Hansen, 2011). It is important to understand the dynamics of the contexts in which this happens, to whom, what forms of discrimination take place, and how this problem can be avoided or dealt with appropriately. This will help physicians, medical students, residents, and patients, along with colleagues of doctors, all coexist - also while reducing one source of stress that these healthcare providers face.

III. Who are the targets?

Essentially anyone can be a target for discrimination. For this paper, we will focus on medical students, medical residents, and practicing physicians as the main targets of discrimination, typically in response to their outward characteristics. In their article, Breuner and Moreno (2011) discussed some factors that doctors possess that may exacerbate their encounters with a difficult patient. They discussed that a doctor's personality, cultural gaps between the patient and provider, or a number of external circumstances may increase the difficulty of an encounter. They also stated that physicians with less experience may be at higher risk for perceiving the encounter as difficult (Breuner \& Moreno, 2011). This could translate from a simple miscommunication between patient and provider, to perceived discrimination by the provider from the patient. This age/experience gap with perceived discrimination between new and older physicians has been documented by two other studies as well. Baldwin \& Daugherty (1997) stated as students transitioned through medical school and residency they reported less experiences of gender discrimination and sexual harassment. They attribute this to the students learning how to prevent, avoid, or handle these unpleasant experiences more effectively as they moved along in their training (Baldwin \& Daugherty, 1997). In a different study by Crutcher et al. (2011) discusses how older medical residents are less likely to report acts of discrimination. They debate whether the older graduates truly experience less of the behaviors, or with increasing age comes increasing maturity and their perceptions and interpretations change. They state that it is also very possible that the perpetrators may also be more keen on targeting younger individuals (Crutcher et al., 2011).

IV. What forms of discrimination are there?

Discrimination takes many different forms and follows many different patterns. The published literature that typically relates to medical student/resident discrimination is difficult to decipher from all the different labels the discriminatory behaviors are given in the various studies, considering there is no definition of the discriminatory actions being grouped under the specific label. The blogs and articles that practicing physicians report on are more specific and easier to group as they tend to relate to one specific topic.

A. Gender Discrimination 
This is shown by the data as one of the most common forms of discrimination in a number of studies in general (Baldwin \& Daugherty, 1997; Fnais et al., 2014; Mavis et al., 2014), and as one of the most common bases for one's perception of discrimination (Baldwin \& Daugherty, 1997; Coombs \& King, 2005; Crutcher et al., 2011). This type of discrimination encompasses a wide range of negative actions, most notably, the wage gap and career advancements which can be due to institutional discrimination or individual discrimination. In a cross-sectional survey of academic emergency departments, Madsen et al. (2017) documented the extent of the wage gap between men and women, and white and non-white academic EM physicians from their analysis consisting of multiple linear regression to compare salaries while controlling for confounding variables (Madsen et al., 2017). The overall general consensus prior to this specific work on the wage gap suggests "gender disparities in salary among academic physicians could be attenuated by adjusting for part time status, clinical hours worked, or leave time (i.e., maternity leave) during the course of physicians' careers" (Madsen et al., 2017). For this reason, Madsen and colleagues adjusted for these issues and conducted the assessment of the salaries of only full-time faculty. They found that these pay gaps still persisted with a $\$ 19,000$ difference between men and women, even when the women were just as, if not more, trained than their male counterparts. They also found that men had a higher starting salary as an instructor by $35 \%$, and $10 \%$ higher starting as an assistant professor. It was also discussed how most instructors and professors, and those who occupied chair/chief, vice chair, and medical director positions were almost completely white males (Madsen et al., 2017). This serves as an example of institutional level discrimination based the data collected. These institutions' ideals are reflected in their persistent wage gap, and their predominantly white, male populationespecially across the academic boards.

Career advancements were discussed as well in some studies as a form of gender discrimination (Coombs \& King, 2005; Sarsons, 2017) and one blog in particular (Brodsky, 2011). A survey of 1,930 practicing physicians in Massachusetts (with a $24 \%$ response rate) conducted by Coombs and King (2005) asked participants to discuss their discriminatory encounters: How often, the type, and the significance (Coombs \& King, 2005). Their findings showed that female physicians are almost five times more likely than males to experience career advancement obstacles, and more than three times as likely to experience disrespectful/punitive actions (Coombs \& King, 2005). Women were significantly more likely than men to experience some form of discrimination during the 12 months prior to the study at $51 \%$, whereas only $31.2 \%$ of men reported these discriminatory acts occurring. Women also felt that more of their discrimination was perceived due to their gender (Coombs \& King, 2005).

Another study focusing on practicing physicians by Heather Sarsons (2017) examined how much more women were punished at work compared to the men when factors like positions or performance was stable (Sarsons, 2017). Her study examined the "Medicare Carrier file, a 20\% random sample of fee-for-service claims of all Medicare beneficiaries in the U.S. between 2008 and 2012" (Sarsons, 2017). The data she focused on pertained to referrals of primary care physicians (PCPs) to surgeons, and then the rate of referrals after a 
surgeon lost the patient. What she found was that women were punished more often than their male counterparts by PCPs (Sarsons, 2017), and it seems a valid reason to promote a pay gap between men and women. It was found that when a PCP referred a patient to a female doctor and the patient died, the number of referrals that PCP sent to that surgeon dropped sharply (59\%), and that drop was then generalized to the rest of the female surgeons that PCP was in contact with. Afterwards, the patients that were referred to those women were much less difficult and risky. On the other hand, when a male doctor lost a patient, there was almost no drop in referrals (Sarsons, 2017). It was also found that PCPs became more optimistic about a male surgeon's ability after a good outcome and increased their referrals by $20 \%$ (Sarsons, 2017). It was noted that this sharp drop in referrals for women was strongest at the beginning of the referral relationship. Overall experience of the PCP and the surgeon seemed to have no influences, and these drops for women and optimistic outlooks for men were unrelated to the PCP's gender (Sarsons, 2017).

There are other forms of gender discrimination that follow along these same lines, pertaining to medical school students and residents directly. In a 2011 retrospective questionnaire survey of 377 family medicine graduates from University of Alberta and University of Calgary who completed resident training between 2001-2005 by Crutcher et al., (2011) found that as a resident, men were more likely to receive extra work as a punishment (39\% vs 12\%) described as a more aggressive form of discrimination (Crutcher et al., 2011). On the other hand, women were more likely to have their privileges/opportunities taken away ( $27 \%$ vs $7 \%$ ) (i.e. being subtly excluded from procedural skill learning opportunities) and was described as a more passive-aggressive form of discrimination. It was stated in this study that there was no significant difference in the prevalence of discrimination between men and women (Crutcher et al., 2011). In a review by Mavis et al. (2014) of the Medical School Graduation Questionnaire pertaining to questions related to mistreatment from 2000-2012 discussed being denied opportunities or rewards as a common form of gender discrimination as well, for most categories of discrimination (racial, gender, sexual) (Mavis et al., 2014). Mavis also discussed another form of discrimination related to gender in the form of lower evaluations or grades as a medical student or resident (Mavis et al., 2014).

Most gray literature focuses on the racial aspect of discrimination, but there is one blog in which a female doctor describes her experience with discrimination on the basis of her gender. Physician Linda Brodsky recalls her experience in an alumnae blog. Becoming a doctor was a dream for her. She graduated medical school and became an academic pediatric otolaryngologist. She rose through the ranks and earned her spot as a full professor, but when it came time to become chair when the position opened up, they were not ready for her to assume the position. After working a bit harder for the spot, she found that she was "grossly" underpaid compared to her male colleagues. She attempted a resolution, but got nowhere so proceeded to federal court. Eight years later, she had her settlement check from the university, but had lost her career as an academic surgeon, was made an outcast, labeled a "'troublemaker"'(Brodsky, 2011). She was ostracized, and it seemed to begin because of how her gender was regarded by her colleagues. 


\section{B. Sexual Harassment}

Sexual harassment can be defined by many parts. According to Frank Till (as cited by Paludi, 1990), sexual harassment can be classified into five district categories:

... generalized sexist remarks and behavior. . .inappropriate and offensive, but essentially sanction-free sexual advances. . .solicitation of sexual activity or other sex-related behavior by promise of reward. . .coercion of sexual activity by threat of punishment. . gross sexual imposition or assault. (p. 25, 35)

For this paper, sexual discrimination and sexual harassment are essentially the same thing, as the majority of the literature reviewed did not specifically note them to be different when defining the sections. In the literature it can be characterized by a variety of ways including: sexual favors for grades, unwanted sexual advances, sexist remarks or names (Mavis et al., 2014), inappropriate/unwanted physical contact (Crutcher et al., 2011), or just plainly called sexual harassment or sexual discrimination - with no actual definition of the behaviors considered (Baldwin \& Daugherty, 1997; Crutcher et al., 2011; Dyrbye et al., 2005; Fnais et al., 2014).

\section{Racial/Ethnic Discrimination}

The previously referenced study by Coombs \& King (2005) on practicing physicians also found that $52 \%$ of non-white physicians had experienced and episode of discrimination in the past 12 months (Coombs \& King, 2005). They also found that those running solo practices were discriminated against less than those in the academic setting (54\% vs $28.1 \%$ ), and racial minorities were statistically more likely than whites to have experienced at least one type of discrimination in their organization (14.3\% vs. 9.9\%) (Coombs \& King, 2005). They also discussed that racial discrimination was most often experienced in the form of career obstacles and disrespectful or punitive actions, rather than hiring obstacles and practice barriers (Coombs \& King, 2005). Madsen et al. (2017) in their study of academic EM physicians, found that underrepresented minorities comprised a small proportion of the academic medicine workforce, and were less likely to hold senior positions which correlated to other previous works. They discussed a different study by Nunez-Smith et al. (2012) that found that black or Hispanic faculty constituted only $5 \%$ of new academic hires, and had to face a significantly longer promotion time compared to the white physicians (as cited by Madsen et al., 2017). This data also correlated to their underrepresented minority group in the study, and found that they also had a similar promotion rate, even if factors such as gender, tenure status, degree, etc, were adjusted for (Madsen et al., 2017). This is study examined both gender and race, and in both instances seem to be an example of institutional discrimination.

Outside of practicing physicians, interestingly enough, a meta-analysis by Fnais et al. (2014) of 51 studies from Medline (1948-2011) and Embase (1980-2011) examining discrimination throughout medicine, listed racial discrimination as one of the lowest occurring forms of discrimination in medical school and during residency (Fnais et al., 2014). This could correlate as well to the seemingly lack of empirical studies done on this specific 
topic pertaining to medicine, as only 10 out of 51 studies presented were on racial discrimination. Mavis and colleagues also had data that supported racial discrimination being one of the lowest forms as well, but when medical students did face racial discrimination, it was in the forms of being denied opportunities or rewards, offensive names or remarks, and/or receiving lower evaluations or grades (Mavis et al., 2014). These two studies seem to concur that during medical school, racial/ethnic discrimination may not be as high as previously thought.

Race is touched on in some published studies as discussed above, but can be consistently found more in the gray literature in the form of self-reports of practicing physicians on blogs and articles. There are multiple examples of this type of discrimination; one in particular that is commonly referenced is a personal essay in the Annals of Internal Medicine by Sachin Jain, MD (2013). It is titled The Racist Patient and discusses one incident in particular where a patient during this physician's final months of residency was outraged that the hospital didn't carry his specific brand of insulin, and Jain was trying to figure out a solution. When the situation escalated the physician was exiting the room and was told "Why don't you go back to India!" (Jain, 2013). He snapped back, inappropriately, and when Jain discussed the incident with a colleague, he was not supported and instead told to apologize to the patient because he was better than that. Another colleague tried to make light of such a racist comment. Jain continued to discuss how he was taught to always try his best to accommodate patients in medical school, but was never taught what to do if a patient lashes out on himself, let alone that this type of behavior was alive and well in medicine (Jain, 2013).

In another article from AAMCNews, Robin Warshaw (2017) discusses some particular physicians' instances with racism. Physician Altaf Saadi, who is Muslim and ethnically Iraqi and Iranian and wears a head scarf - and is the chief resident in neurology at two hospitals, recalled one instance in particular where a patient angrily requested to know what foreign medical school she had attended. Her reply was Harvard Medical school, and the patient remained quiet from then on. She discussed that patients aren't always so rude, but will still question where she received her education based on their perceptions of her outward appearance. She also states in medical school, both she and her African American friend were routinely mistaken for janitors, and had to wear their white coats as not to be perceived as anything less (Warshaw, 2017). Another example from this article comes from Leon McDougle, MD, when as an intern was asked not to handle a delivery due to objections about his race from the expectant father. His senior resident spoke to the couple and McDougle then handled the procedure (Warshaw, 2017).

Racism in Medicine: An open secret, an article from CNN, discussed the motives behind a study by Whitgob et al. (2016) and the experiences of physician Sachin Jain (2013) leading to his essay. They also share another new story. This was an instance of racial discrimination, but outside of the hospital. Physician Tamika Cross, an African American OB/GYN, was on a flight when a man became unresponsive, and subsequently flight attendants asked if anyone could help. When she raised her hand, the response was "“Oh, no, sweetie, put your hand down, we are looking for actual physicians or nurses or some type of medical personnel; we 
don't have time to talk to you"' (Howard, 2016). Cross tried further to inform them she was a physician, but was cut off and asked for credentials. When a white man approached the attendant, no questions were asked of him and Cross was told to remain seated (Howard, 2016). This highlights an important idea that discrimination towards a physician of color can be found everywhere, not just from a patient in a hospital or some colleagues.

One more example of the endlessly flowing articles of racial discrimination against physicians comes from The Oregonian newspaper. Samantha Swindler (2017) covers a series of tweets by Esther Choo, MD, MPH, who herself has an impressive background in medicine and teaching, describing her encounters with discrimination in the emergency room. Choo states how "'We've got a lot of white nationalists in Oregon,"” (Swindler, 2017) and that causes a refusal for her care every now and then, as she is an Asian-American doctor. She goes on to say how the racism she experiences, pretty regularly from everyone, seems like isolated experiences when really this happens to other physicians of color all the time. Most times she receives this discrimination is in less overt ways. Some examples are "Where's the real doctor," and "My, you speak English well"' (Swindler, 2017). Yes, she does: she grew up in the US. She goes on to talk about how hard this can be, to deal with these patients, or one instance where a man arrives into the ER covered in swastika tattoos. In those cases, she works to separate her gut reaction and proceed to take care of the patient (Swindler, 2017).

These are just some of the multitudes of examples present online about racial discrimination. This is a problem, especially for practicing physicians, an even though not as common as it seems from the data on medical students and residents, it is still something not enough people are talking about.

\section{Commonly Noted Forms of Discrimination}

Two of the most common forms of discrimination come in the form of verbal comments and humiliation and belittlement (Baldwin \& Daugherty, 1997; Fnais et al., 2014; Mavis et al., 2014). Verbal abuse seems self-explanatory but humiliation and belittlement need some defining. In the literature however, there are no examples in these studies of what constitutes these actions deeming it difficult to know for sure what humiliation and belittlement look like acted out according to these authors.

\section{E. Specifically Noted Forms of Discrimination}

There are also some very specific examples in literature that are not as commonly studied but still present as a problem that may be occurring still in the medical training and practicing community. They are as follows: threat's to one's career or reputation, disparaging comments about a career in medicine (Baldwin \& Daugherty, 1997), hiring obstacles, practice barriers (Coombs \& King, 2005), and the least common form but still briefly discussed: physical abuse (Baldwin \& Daugherty, 1997; Dyrbye et al., 2005; Fnais et al., 2014). Some of these examples seem like they could fall into one of the categories above, but the lacking explanations in the studies it is hard to pinpoint how they should be categorized. 
Age discrimination is noted too, but only one blog discusses this type of discrimination in any depth (Morris, 2014). The physician commented that in the medical profession that age discrimination (or ageism) presents itself as stereotypes of old doctors. They are seen as insufficient, slow, cognitively impaired, and potentially "dangerous". Morris recommends that instead we should be approaching this with a much more positive lens. We should be encouraging older doctors to achieve their full potential, and judge them by their merits, not stereotypes (Morris, 2014).

\section{F. Recrimination for Reporting}

In these instances, it would seem beneficial to report an act of discrimination and get it resolved. However, that is not often the case. Coombs and King (2005) discussed their findings about reporting discrimination. They said that $11.3 \%$ (50 respondents) of their survey respondents had reported and incident of discrimination, and of that $11.3 \%, 52 \%$ reported that they were not satisfied with their organization's response. When asked if the situation had changed, less than one-third reported it had improved, while almost 19\% said the situation had worsened (Coombs \& King, 2005). Crutcher et al. (2011) also examined reports of discrimination and found that $54.4 \%$ (205 out of 377 ) of the graduates knew about the process, meaning about half was unaware (Crutcher et al., 2011). Another study by Mavis et al. (2014) found that out of 151,306 medical students over the 11-year span of data, 24,200 , or about one-third, who were discriminated against actually reported the incidence to faculty or administration. They go on to discuss that for those who did not report their incidences with some motives including that the incident was not important enough or that they feared reprisal. A smaller percentage of those that didn't report (29\%) were just unsure of what to do. It seems they did a follow up the year after their normal set of data, and found that $37 \%$ decided that reporting the incidence would be ineffective, and $22 \%$ indicated they have resolved the situation themselves (Mavis et al., 2014).

V. Who are the perpetrators?

\section{A. Supervisors/Administration}

Where the discrimination comes from depends on where you are throughout this process. As a medical student, resident, or practicing physician, it is often discussed that discrimination comes from someone in charge mostly. For medical students, this includes attending physicians, nurses, specialty physicians, support staff, and older residents. The studies overall seem to deem physicians as the most common perpetrator, followed by residents, clinical faculty, support staff, nurses, and patients (Baldwin \& Daugherty, 1997; Crutcher et al., 2011; Dyrbye et al., 2005; Mavis et al., 2014). For residents, the general trend is the same from where the discrimination comes from, except there seem to be a heavier focus on physicians as the perpetrators, followed by mainly older residents, and residents of the same age are also seen as perpetrators (Baldwin \& Daugherty, 1997). As a practicing physician, most discrimination seems to come from supervisors and administration including their employers, followed by colleagues then nursing staff and other support staff as described by gray and peer-reviewed literature (Brodsky, 2011, 2011; Coombs \& King, 
2005; Dyrbye et al., 2005; Mavis et al., 2014; Morris, 2014). As most of these acts of discrimination come from another person and are directed to another person, this can be seen as instances of individual level discrimination. Although, some instances of employer level or administrative level discrimination could constitute as institutional level discrimination.

\section{B. Colleagues/Peers}

The data for peer discrimination during medical school and first year residency is only discussed briefly in one study, and it was found that the majority of reports of discrimination were from older residents for both medical students and residents. It was also found that medical students were also discriminated by others at their same experience level, and also that the first year residents were discriminated against by other first year residents at their same experience level (Baldwin \& Daugherty, 1997). As a practicing physician, there are only some peer-reviewed studies discussing discrimination from colleagues. Coombs and King (2005) discusses how discrimination from colleagues was ranked the second highest out of 5 categories (Coombs \& King, 2005). Sarsons (2017) also discusses her study on referrals that is based off of the actions between colleagues (Sarsons, 2017). Most other literature from doctors reporting discrimination from colleagues comes from the area of gray literature. Lots of articles and blogs discuss specific instances between colleagues, amongst other perpetrators, and how their thoughts and lives were affected (Brodsky, 2011; Chen, 2013). Discrimination amongst colleagues in this fashion could be categorized as individual level discrimination.

\section{Patients}

This would seem most anticipated source of discrimination, but is actually one of the less common sources among studies for residents that include this option (Baldwin \& Daugherty, 1997; Crutcher et al., 2011), and for the study on practicing physicians that includes this category (Coombs \& King, 2005). Whitgob and colleagues do discuss however, from their perception this seems to be something common among residents, which is why they completed the study on ways to combat these incidences (Whitgob, Blankenburg, \& Bogetz, 2016). Though this type of discrimination can be the most hurtful as it typically involved disparaging comments about the physician performing their duties, it is cited in the peerreviewed literature as the least common which is a positive. In the gray literature however, this is often talked about as one of the seemingly most common forms of discrimination against a practicing physician (Chen, 2013; Swindler, 2017; Warshaw, 2017). From this authors point of view, patients seem particularly keen to feel the need to discriminate against someone of a different race. This would also be considered individual discrimination.

VI. What is the awareness if out there?

There has been awareness on this topic for some time. It is noted that HK Silver called attention to "“"medical student abuse", early around 1982, but first report of any quantitative studies didn't come around until 1988 (Baldwin \& Daugherty, 1997). The first concern was medical students receiving discrimination as they made their way through medical school, wherein that process is already inherently difficult. There seems to be communication through 
researchers since then. Baldwin and Daugherty (1997) cite Silver and his 1982 paper, Medical Students and Medical School, discussing how he was the first to shine light onto this topic. Baldwin and Daugherty (1997) continue on with their study, Do Residents Also Feel "Abused"? Perceived Mistreatment During Internship, showing that there were common types of discriminatory behaviors acted against medical students and first year residents. They were also able to describe where those actions stemmed from. They followed up with a number of papers, subsequently cited by numerous others studying this topic. The literature seems to take another step forward with a study by Crutcher et al., (2011), Family Medicine Graduates' Perceptions of Intimidation, Harassment, and Discrimination During Residency Training. They found more ways in which discriminatory actions may expressed towards medical students, and on what basis those discriminated against perceived the cause of the behavior to be. Fnais et al. (2014) continue in this seemingly growing discourse with a large meta-analysis of 51 studies, including various Baldwin and Daugherty studies and the previously mentioned study by Crutcher and colleagues on discrimination against medical students and residents, documenting the average frequency and types of discriminatory behaviors most commonly found in the previous studies.

Thus far, there have been many studies describing in each their own way the specific or general types of discrimination or mistreatment that has been going on in medical schools for seemingly quite some time, and it is safe to assume probably longer. The literature does discuss many ways that discrimination can be experienced, and often where it comes from, but a strong solution has been consistently lacking. This problem seems to be addressed with Whitgob et al., (2016) and their current analysis. She witnessed her own act of discrimination against a resident she was overseeing and realized she didn't know how to handle that confrontation, nor had she learned how to respond to any type of discriminatory situation as such. In her study she wanted to create strategies for trainees (residents) and physicians to deal with discrimination from patients towards providers. The outcome after conducting her one-on-one interviews among a small sample size of pediatric faculty are these four steps as follows:

Assess Illness Acuity (How sick is the patient? Is finding another provider at your institution an option?); Cultivate a Therapeutic Alliance (Build rapport, Educate the family on the team structure: "If you're here in the teaching facility, everybody participates and that's part of the bargain of having access to the expertise and participation of multiple people."); Depersonalize the Event (Remember discrimination is often motivated by patients' fears and anxiety about the unknown. Acknowledge that discrimination may be coming from family's lack of control.); Ensure a safe learning Environment for Trainees (Provide support and assurance of trainee competence: "I would trust this physician to take care of my own children"; "I agree with this physician. What other questions may I answer?") (Whitgob et al., 2016).

Though this has not been cited yet, it seems to this author as a stepping stone in this discourse, it may just be that it is still quite recent and has not had the full time to circulate just yet. It seems that this is a valuable step towards confronting the issues of discrimination against residents. 
In a follow-up article by CNN, Jacqueline Howard discusses Whitgob's turning moment that set her off to complete her study with her colleagues (Howard, 2016). Howard also discusses the American Medical Association's (AMA) response to this type of patient discrimination. They state that their code of ethics doesn't specifically address this type of discrimination against doctors by patients, but does offer ethical guidance for disruptive behavior. The code recommends:

. . terminate the patient-physician relationship with a patient who uses derogatory language or acts in a prejudicial manner only if the patient will not modify the conduct. In such cases, the physician should arrange to transfer the patient's care. (as cited by Howard, 2016)

This is interesting since a recent qualitative assessment by Emile et al., (2017) discussed discriminatory behavior from patients in a different light (Paul-Emile, Smith, Lo, \& Fernández, 2016). They seem to agree and discuss that physicians and hospitals could very well accommodate appropriately if the refusal may be for religious reasons, having a bad past experience with a physician of a certain race, a possible PTSD trigger, or even cognitive impairment like dementia. They state how in these times, it is probably just best to accommodate rather than fight the patients or try and delve into their feelings — so long as the patient is not in need of immediate care (Paul-Emile et al., 2016). However, for the patients that are refusing care from a physician because of outright racism, bigotry, or sexist views, need to be confronted and should not be accommodated. They suggest that accommodating such behaviors is nothing more than a reinforcement on these poor behaviors and it is best to explain to the patient that their behavior and remarks are inappropriate and will not be tolerated (Paul-Emile et al., 2016).

It should be noted that nowhere in the literature that was found or reviewed for this literature review, gray or peer-reviewed, does it mention ways to deal with discrimination from all the other avenues discussed here including from colleagues and peers, supervisors (including employers, attending physicians, and nurses, and supporting staff).

VII. Is this unique to medicine?

No, this is not something unique to medicine and appears to be a common phenomenon to be discriminated against in some form or another at some point, seemingly since most of the population regards something about someone else as offensive. This extends beyond medicine and may be found in psychiatry, policing, astronomy; evidence even exists that infants can be the target of discrimination. A brief study by Esmail \& Everington (1993) discusses that job applicants of ethnic minority groups are more often shortlisted for the same jobs compared to white applicants. According to their study, though unable to be conducted to completion, white applicants were twice as likely to be selected for the same positions compared to racial minorities (Esmail \& Everington, 1993). In a different study, social psychologists Swencionis \& Goff (2017) discuss the many factors responsible for discrimination in policing. They find that there are specific factors that influence a police officer to enact discriminatory behavior as they interpret the suspect as such (i.e. trait-based prejudices, authoritarianism, etc.). They conclude that there are ways to avoid these poor-ending discriminatory encounters, but still more empirical 
research needs to be conducted (Swencionis \& Goff, 2017). In a totally different area of research, Clancy et al. (2017) discuss the hostile work environments that women, specifically women of color, experience in the field of astronomy and related (Clancy, Lee, Rodgers, and Richey, 2017). The survey conducted found that experiences related to a hostile work environment depended on gender, race, and career rank. The authors discuss that women, especially if lower in the hierarchy of positions to be held, tend to be harassed and assaulted and flooded with negative remarks. Women of color seemed to have the worst of it, with the data supporting that they were more likely than other women to report instances of physical harassment (Clancy et al., 2017). One last example from Wolf and colleagues in the United Kingdom discusses implicit prejudice against infants (Wolf, Maio, Karremans, \& Leygue, 2017). The authors found that regardless whether the target was an adult, child, or infant, the white European participants preferred their racial in-group members opposed to their racial out-group of South Asian targets (Wolf et al., 2017). This demonstrates the widespread nature of discrimination.

VIII. What are the next steps?

\section{A. Training and Support Against Discrimination}

As this literature review has demonstrated, discrimination experienced by healthcare providers is a big problem, and not enough people seem to be talking about it for a change to be made. Whitgob and colleagues addressed some ways to deal with discriminatory patients, as did Dyrbye and colleagues (Dyrbye et al., 2005; Whitgob et al., 2016). But what do you do when you are already a practicing physician and no longer are in school to be trained? The AMA should to set up some strict guidelines, more than mere, recommendations, about how clinical institutions should handle discriminatory behavior whether originating from patients, medical staff, nonmedical staff, or administrators. Numerous studies have identified forms of discriminatory behaviors out there and where they come from, but now is the time to look and find ways to handle these actions, appropriately. There seems to be a starting point in place already of how to help trainees respond to discrimination from patients, and now we can transfer this knowledge higher up in the ranks to practicing physicians and alter it as necessary.

As previously stated, the majority of physicians have a lot of other stressors to face, some on an almost daily basis. These stressors along with discrimination can end up causing physicians to make medication errors, and overall just have a poor sense of health feel a need to switch professions. Stressors like burnout, depression, compassion fatigue, etc. follow those in practice, and discrimination seems like it would most likely exacerbate these existing problems. A further study to assess the correlation between worsening stressors and experiences of discrimination may be useful in this topic of study.

Overall, there has to be a good support network in these for those dealing with discrimination. If someone reports and act of discrimination, it needs to be handled appropriately without a fear of backlash. If a patient refuses a physician due to some unvalidated sexist or racial reason, the physician needs the support of upper management and from the colleagues they are working with. With adequate support and training, there may be 
a way to decrease the reports of discrimination in the healthcare setting. Not every perpetrator can be changed. Discrimination is based in part on one's understanding of a situation or of another's physical characteristics, but it can be improved to some extent.

This literature review covered studies of discrimination from medical school, through residency, and as a practicing physician. Types of discrimination, sources of discrimination, and possible ways to help this problem were discussed and identified. It is up to individuals with the power to act now to keep moving forward and find ways to help those whose job it is to help us. 


\section{References}

American Medical Association. Chapter 1: Opinions on patient-physician relationships. Retrieved March 23, 2018, from http://i2.cdn.turner.com/cnn/2016/images/10/26/ama.medical. code.of.ethics.pdf

Amanullah, S., McNally, K., Zelin, J., Cole, J., \& Cernovsky, Z. (2017). Are burnout prevention programs for hospital physicians needed? Asian Journal of Psychiatry, 26(Supplement C), 6669. https://doi.org/10.1016/j.ajp.2017.01.009

Baldwin, D. C. J., \& Daugherty, S. R. (1997). Do residents also feel “abused”? Perceived mistreatment during internship. Academic Medicine, 72(10), S51-S53.

Baumeister, R. \& Vohs, K. D. (2007). In Encyclopedia of Social psychology. Thousand Oaks, Calif.: Sage Publications.

Breuner, C. C., \& Moreno, M. (2010). Approaches to the difficult patient/parent encounter. Pediatrics, 127, 163-169. doi:10.1542/peds.2010-0072

Brodsky, L. (2011). Women doctors still face discrimination - Bryn Mawr Alumnae Bulletin. Retrieved September 28, 2017, from http://bulletin.brynmawr.edu/articles/oped-linda-brodskyaugust-2011/

Chen, P. (2013). When the patient is racist. Retrieved September 25, 2017, from https://well.blogs.nytimes.com/2013/07/25/when-the-patient-is-racist/

Clancy, K. B. H., Lee, K. M. N., Rodgers, E. M., \& Richey, C. (2017), Double jeopardy in astronomy and planetary science: Women of color face greater risks of gendered and racial harassment, $J$. Geophys. Res. Planets, 122, 1610-1623, doi:10.1002/2017JE005256

Coombs, A. A. T., \& King, R. K. (2005). Workplace discrimination: Experiences of practicing physicians. Journal of the National Medical Association, 97(4), 467-477. 
Crutcher, R. A., Szafran, O., Woloschuk, W., Chatur, F., \& Hansen, C. (2011). Family medicine graduates' perceptions of intimidation, harassment, and discrimination during residency training. BMC Medical Education, 11, 88. https://doi.org/10.1186/1472-6920-11-88

Dyrbye, L. N., Thomas, M. R., \& Shanafelt, T. D. (2005). Medical student distress: Causes, consequences, and proposed solutions. Mayo Clinic Proceedings, 80(12), 1613-1622. https://doi.org/10.4065/80.12.1613

Esmail, A., \& Everington, S. (1993). Racial discrimination against doctors from ethnic minorities. BMJ : British Medical Journal, 306(6879), 691-692.

Fahrenkopf, A. M., Sectish, T. C., Barger, L. K., Sharek, P. J., Lewin, D., Chiang, V. W., . . Landrigan, C. P. (2008). Rates of medication errors among depressed and burnt out residents: prospective cohort study. BMJ, 336(7642), 488-491. https://doi.org/10.1136/bmj.39469.763218.BE

Fiske, S., Gilbert, D. T., Lindzey, G., \& Jongsma, A. E. (2010). Handbook of social psychology (5th ed.). Hoboken, N.J.: Wiley.

Fnais, N., Soobiah, C., Chen, M. H., Lillie, E., Perrier, L., Tashkhandi, M., .. . Tricco, A. C. (2014). Harassment and discrimination in medical training: A systematic review and meta-analysis. Academic Medicine, 89(5), 817-827. https://doi.org/10.1097/ACM.0000000000000200

Howard, J. (2016). Racism in medicine: An “open secret.” Retrieved September 28, 2017, from http://www.cnn.com/2016/10/26/health/doctors-discrimination-racism/index.html

Jablow, M. (2017). Compassion fatigue: The toll of being a care provider. Retrieved September 5, 2017, from https://news.aamc.org/medical-education/article/compassion-fatigue-toll-being-careprovider/?utm_source=newsletter\&utm_medium=email\&utm_campaign=AAMCNews071217

Jain, S. (2013). The racist patient. Annals of Internal Medicine 158(8), 632. 
Madsen, T. E., Linden, J. A., Rounds, K., Hsieh, Y.-H., Lopez, B. L., Boatright, D., . . Safdar, B. (2017). Current status of gender and racial/ethnic disparities among academic emergency medicine physicians. Academic Emergency Medicine, 224(10), 1182-1192. https://doi.org/10.1111/acem.13269

Mavis, B., Sousa, A., Lipscomb, W., \& Rappley, M. D. (2014). Learning about medical student mistreatment from responses to the medical school graduation questionnaire. Academic Medicine, 89(5), 705-711. https://doi.org/10.1097/ACM.0000000000000199

Morris, D. P. (2014). Ageism and age discrimination - against doctors. Retrieved September 28, 2017, from http://www.drphilipmorris.com/ageism-and-age-discrimination/

Myers, D. G., \& Twenge, J. M. (2017). Social Psychology (12th ed.). New York, NY: McGraw-Hill. Nunez-Smith, M., Ciarleglio, M. M., Sandoval-Schaefer, T., Elumn, J., Castillo-Page, L., Peduzzi, P., \& Bradley, E. H. (2012). Institutional Variation in the Promotion of Racial/Ethnic Minority Faculty at US Medical Schools. American Journal of Public Health, 102(5), 852-858. https://doi.org/10.2105/AJPH.2011.300552

Outten, C. (2017). Research Guides: Gray Literature: Gray Literature. Retrieved March 2, 2018, from //csulb.libguides.com/c.php?g=39129\&p=249422

Paludi, M. A. (1990). Ivory Power: Sexual Harassment on Campus. SUNY Press. (pp. 25, 35)

Paul-Emile, K., Smith, A. K., Lo, B., \& Fernández, A. (2016). Dealing with racist patients. New England Journal of Medicine, 374(8), 708-711. https://doi.org/10.1056/NEJMp1514939

Swencionis, J. K., \& Goff, P. A. (2017). The psychological science of racial bias and policing. Psychology, Public Policy, and Law, 23(4), 398-409.

http://dx.doi.org.proxy.lib.pdx.edu/10.1037/law0000130 
Swindler, S. (2017). Portland doctor Esther Choo responds to racism in the emergency room. Retrieved September 28, 2017, from http://www.oregonlive.com/portland/index.ssf/2017/08/portland_doctor_responds_to_ra.html

Till, F. J. (1980). Sexual Harassment. A Report on the Sexual Harassment of Students. National Advisory Council on Women's Educational Programs, 1832 M Street, N. Retrieved from https://eric.ed.gov/?id=ED197242

Warshaw, R. (2017). When the target of bias is the doctor. Retrieved September 5, 2017, from https://news.aamc.org/patient-care/article/target-biasdoctor/?utm_source=twitter\&utm_medium=social\&utm_campaign=AAMCSocial20170509

Whitgob, E. E., Blankenburg, R. L., \& Bogetz, A. L. (2016). The discriminatory patient and family: Strategies to address discrimination towards trainees. Academic Medicine, 91(11), S64-S69. https://doi.org/10.1097/ACM.0000000000001357

Wolf, L. J., Maio, G. R., Karremans, J. C., \& Leygue, C. (2017). On implicit racial prejudice against infants. Group Processes \& Intergroup Relations, 20(6), 789-800.

https://doi.org/10.1177/1368430216629812 